\title{
Celecoxib suppresses fibroblast growth factor-2 expression in pancreatic ductal adenocarcinoma PANC-1 cells
}

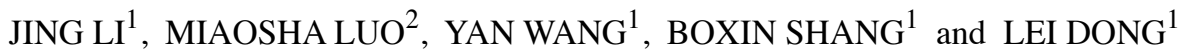 \\ ${ }^{1}$ Department of Gastroenterology, The Second Affiliated Hospital of Xi'an Jiaotong University Health Science Center, \\ Xi'an, Shaanxi 710004; ${ }^{2}$ The First Affiliated Hospital of Xi'an Jiaotong University \\ Health Science Center, Xi'an, Shaanxi 710000, P.R. China
}

Received January 18, 2016; Accepted March 16, 2016

DOI: $10.3892 /$ or.2016.4924

\begin{abstract}
The inhibition of cyclooxygenase (COX)-2 has been reported to suppress growth and induce apoptosis in human pancreatic cancer cells. Nevertheless, the precise biological mechanism of how celecoxib, a selective COX-2 inhibitor, regulates the growth and invasion of pancreatic tumors is not completely understood. It has been shown that fibroblast growth factor-2 (FGF-2) and its receptor levels correlate with the inhibition of cancer cell proliferation, migration and invasion in pancreatic ductal adenocarcinoma (PDAC). Therefore, the aim of the present study was to examine the hypothesis that the antitumor activity of celecoxib in PDAC may be exerted through modulation of FGF-2 function. In the present study, we evaluated the effects of celecoxib on the proliferation, migration, invasion and apoptosis of the PANC-1 cell line. Western blotting and quantitative real-time polymerase chain reaction (qRT-PCR) were used to examine the expression of FGF-2, FGFR-2, ERK1/2 and MMPs. In the present study, FGF-2 and FGFR-2 were expressed in PANC-1 cells and FGF-2 exerted a stimulatory effect on phosphorylated extracellular signal regulated kinase (p-ERK) expression. Celecoxib treatment suppressed FGF-2 and FGFR-2 expression and decreased MMP-2, MMP-9 and p-ERK expression in the PANC-1 cells. Furthermore, celecoxib treatment caused the resistance of PANC-1 cells to FGF-2 induced proliferation, migration and invasion ability, as well as the increase in their
\end{abstract}

Correspondence to: Professor Lei Dong, Department of Gastroenterology, The Second Affiliated Hospital of Xi'an Jiaotong University Health Science Center, West 5th Road, Xi'an, Shaanxi 710004, P.R. China

E-mail: donglei556@sina.com

Abbreviations: COXs, cyclooxygenases; FGFs, fibroblast growth factors; PDAC, pancreatic ductal adenocarcinoma; ERK, extracellular signal-regulated kinase; MMPs, matrix metalloproteinases; TIMPs, tissue inhibitor of metalloproteinases

Key words: celecoxib, ERK1/2, FGF-2, invasion, migration, PANC-1 apoptotic rate. Our data provide evidence that targeting FGF-2 with celecoxib may be used as an effective treatment in PDAC.

\section{Introduction}

Pancreatic ductal adenocarcinoma (PDAC) is one of the most aggressive human malignancies and it is the fourth leading cause of cancer-related death in the US (1). Due to its late presentation, early local invasion and metastatic potential longterm survivors are rare. Clinical trials performed in PDAC patients using different chemotherapeutic agents have only slightly improved their survival over the last few decades, and the overall 5-year relative survival rate remains at $6.9 \%(2,3)$. In addition, more than $80 \%$ of patients have advanced regional disease or distant metastasis at the time of diagnosis and tumors are often inoperable. Moreover, those patients who undergo surgical tumor resection exhibit a high incidence of local recurrence, peripheral organic metastasis and peritoneal dissemination (4).

At the molecular level, a high percentage of PDACs overexpress a number of growth factors and their receptors, including the epidermal growth factor family, transforming growth factor family and fibroblast growth factor family (5). Fibroblast growth factors (FGFs) are comprised of $\sim 20$ molecules with a wide range of biological actions. They have the ability to stimulate angiogenesis, and are involved in cell differentiation, migration, tissue repair and regeneration (6). The two most extensively studied FGFs are FGF-1 and FGF-2 (7). FGF-2 is the prototypic heparin-binding protein with growth, anti-apoptotic and angiogenic activity (8). It is overexpressed in PDAC (9), and the FGF-2 receptor has been reported to correlate with tumor metastasis, stage and retroperitoneal invasion (10). In addition, low expression of FGF-2 has been associated with longer post-operative survival in PDAC patients (11). In general, FGF-2 can exerts its biological effects by binding to FGFR-2, which leads to the activation of a number of signaling cascades; in which the most dominant is the MAPK/ERK pathway (12).

Cyclooxygenases (COXs) are key enzymes in the synthesis of prostaglandins. There are two types of COX isoenzymes: COX-1, which is expressed in many normal tissues and responsible for many physiological functions; and COX-2, an inducible prostaglandin synthase that is upregulated in 
different tumor tissues and in response to inflammation (13). Celecoxib is a selective COX-2 inhibitor that was first used for adjuvant treatment in patients with familial adenomatous polyposis (14). Since the introduction of celecoxib in cancer therapy, a number of studies have investigated molecular targets and the clinical effects of selective COX-2 inhibitors, as well as molecular mechanisms of their antitumor activity, either via selective COX-2 inhibition or COX-2-independent mechanisms of action. It has been shown in pre-clinical studies of pancreatic cancer that selective COX-2 inhibitors exert their antitumor effect by inhibiting cell proliferation and promoting apoptosis (15). Furthermore, although precise biological mechanisms underlying the antitumor effect of COX-independent action remain unclear, it is possible that the effect of COX-2 inhibitors may be mediated, at least in part, by the suppression of FGF-2 (16). It has been shown that oral COX-2 inhibitors suppress angiogenesis and the growth of gastrointestinal tumor explants in nude mice, possibly via mechanisms associated with the reduced expression of FGF-2 and VEGF (17). Furthermore, in esophageal adenocarcinoma, treatment of Seg-1 cells with NS-398 in vitro significantly reduced FGF-2 expression and induced an antitumor effect (18).

Based on these findings, it is possible that the antitumor mechanisms of celecoxib may be associated with FGF-2 signal regulation. Therefore, the aim of the present study was to examine the hypothesis that selective COX-2 inhibitor celecoxib may synergistically suppress the expression of FGF-2 (possibly through the activation of ERK1/2 and increase in the secretion of MMPs) and the expression of its receptor, FGFR-2; thereby, inhibiting proliferation, invasion and migration, and stimulating the apoptosis of human pancreatic cancer PANC-1 cells in vitro.

\section{Materials and methods}

Reagents. Dulbecco's modified Eagle's medium (DMEM) was obtained from HyClone (Logan, UT, USA), and penicillin and streptomycin were acquired from Gibco-BRL (Gibco, NY, USA). Celecoxib was obtained from Sigma-Aldrich (St. Louis, MO, USA) and dissolved in anhydrous dimethyl sulfoxide (DMSO) (Sigma, St. Louis, MO, USA) at a concentration of $100 \mathrm{mmol} / \mathrm{l}$ for storage solution. Human FGF-2 was obtained from Cell Signaling Technology (Boston, MA, USA), and 3-(4,5-dimethylthiazol-2-yl)-2,5-diphenyltetrazolium bromide (MTT) was obtained from Sigma Chemicals (Sigma). Other reagents were purchased from Nanjing Chemical Reagent Co. (Nanjing, China) unless otherwise described.

Cell culture. PANC-1 cells derived from a human PDAC were acquired from the Cell Bank of the Chinese Academy of Sciences (Shanghai, China). Cells were cultured in DMEM with $10 \%$ fetal bovine serum (FBS; Gibco, Grand Island, NY, USA) and $1 \%$ ampicillin-streptomycin. Cells were grown in a humidified incubator with an atmosphere of $5 \% \mathrm{CO}_{2}$ at $37^{\circ} \mathrm{C}$.

Cell viability assay. PANC-1 cells were cultured in 96-well plates at a density of $1 \times 10^{4}$ cells/well and incubated in medium with $10 \%$ FBS. After overnight growth, the cells were treated with $5,10,20,40,80$ and $160 \mu \mathrm{mol} / 1$ of celecoxib in serumfree conditions. The control group was set in serum-free medium. After incubation for 24,48 and $72 \mathrm{~h}$ at $37^{\circ} \mathrm{C}, 20 \mu \mathrm{l}$ of MTT solution [5 $\mathrm{mg} / \mathrm{ml}$ in phosphate-buffered saline (PBS)] was added into each well; and cells were further incubated for $4 \mathrm{~h}$ at $37^{\circ} \mathrm{C}$. Next, $100 \mu \mathrm{l}$ of DMSO was added into each well at $37^{\circ} \mathrm{C}$. A spectrophotometer (Bio-Rad, Hercules, CA, USA) was used to determine the optical density (OD) value of each well at $490 \mathrm{~nm}$. Each experiment was performed at least in triplicate, and results are presented as a relative ratio to the OD at the beginning of the experiment.

Cell apoptosis assay. In order to quantify apoptosis, the cells were stained with Annexin V and propidium iodide (PI) using an Annexin V-FITC/PI apoptosis kit (BD Biosciences, San Jose, CA, USA) according to the manufacturer's instructions. In brief, PANC-1 cells were cultured into 6-well plates with DMEM containing $10 \%$ FBS for $24 \mathrm{~h}$. Next, the cells were further treated for $24 \mathrm{~h}$ with an indicated concentration of celecoxib or FGF-2. After treatment, the cells were digested with trypsin, washed twice with cold PBS, and resuspended in $1 \mathrm{X}$ binding buffer at a concentration of $1 \times 10^{5}$ cells $/ \mathrm{ml}$. Next, $100 \mu \mathrm{l}$ of the solution ( $1 \times 10^{5}$ cells) was mixed with $5 \mu \mathrm{l}$ of Annexin V-FITC and $5 \mu \mathrm{l}$ of PI, and incubated for $15 \mathrm{~min}$ in the dark at room temperature. Finally, $400 \mu \mathrm{l}$ of $1 \mathrm{X}$ binding buffer was added to each sample; then, the cells were kept on ice and immediately subjected to flow cytometry on a FACSCalibur flow cytometer (Becton-Dickinson, San Jose, CA, USA). Cell Quest software (Becton-Dickinson) was used to analyze the data.

Invasion assay. For the cell invasion assay, the cells were pretreated with the indicated celecoxib or FGF-2 concentration for $2 \mathrm{~h}$, digested with trypsin and placed in the upper compartment of a Matrigel (BD Biosciences)-coated chamber, as previously described (19). In brief, equal concentrations of cells $\left(5 \times 10^{4}\right.$ cells/well) were suspended in $300 \mu 1$ of DMEM containing $0.1 \%$ of BSA, and the cell suspensions were added to the upper compartment of a 24-well Boyden chamber (Millipore Co., Billerica, MA, USA). Another $600 \mu 1$ of DMEM containing $15 \%$ FBS was added to the lower compartment in order to stimulate cell invasion. Then, the cells were incubated for $24 \mathrm{~h}$, and the non-invaded cells were removed from the top compartment of the membrane with a cotton swab. Remaining cells on the lower surface of the membrane were fixed with $4 \%$ paraformaldehyde and stained in $0.01 \%$ crystal violet solution. The number of invading cells was quantified from six random high-power fields (HPFs) visualized at a magnification of x100.

Scratch migration assay. For the evaluation of PANC-1 cell migration, the cells were cultured in 6-well plates ( $1 \times 10^{6}$ cells/well) for $24 \mathrm{~h}$, washed with PBS twice and treated with the indicated concentration of celecoxib or FGF-2 for $2 \mathrm{~h}$. Then, the cells were scraped with the fine end of a 1-ml pipette tip; and the plates were washed twice with PBS to remove the detached cells, and were incubated with DMEM containing $10 \%$ FBS. Cell migration was photographed using $10 \mathrm{HPFs}$ at 0 - and 24-h post-induction of the injury. Remodeling was measured as the relative diminishing area across the induced injury, and expressed as migration area percentage.

Western blot analysis. For western blot analysis, PANC-1 cells were washed twice with cold PBS and lysed in RIPA 
buffer (PBS containing 1\% Nonidet P-40, 0.5\% sodium deoxycholate, $0.1 \%$ SDS, $100 \mathrm{ng} / \mathrm{ml}$ of phenylmethylsulfonyl fluoride and $10 \mu \mathrm{g} / \mathrm{ml}$ of aprotinin). Then, the samples that contained $50 \mu \mathrm{g}$ of protein/lane were fractionated on a $10 \%$ SDS-polyacrylamide gel by electrophoresis, and the separated proteins were transferred onto polyvinylidene difluoride (PVDF) membranes (Millipore) using a semi-dry transfer cell (Bio-Rad). Next, the blots were incubated in Tris-buffered saline (TBS; $10 \mathrm{mmol} / \mathrm{l}$ of Tris- $\mathrm{HCl} \mathrm{pH} 8.0$ and $150 \mathrm{mmol} / \mathrm{l}$ of $\mathrm{NaCl}$ ) containing $5 \%(\mathrm{w} / \mathrm{v})$ non-fat dry milk and $0.1 \%$ Tween- 20 for $2 \mathrm{~h}$ at room temperature. Then, the immunoblots were incubated first with different specific primary antibodies, followed by incubation with appropriate secondary antibodies. $\beta$-actin was used as a control. Signals were quantified using the public domain NIH ImageJ 1.49 (http://rsbweb.nih.gov/ij/ download.html; US National Institutes of Health, USA).

The following primary antibodies were used: mouse anti-human FGF-2 antibody (catalog no. ab130094; dilution 1:500; Abcam, Cambridge, MA, USA), rabbit anti-human FGF receptor 2 antibody (catalog no. 11835; dilution 1:500), rabbit anti-human p44/42 MAPK antibody (catalog no. 9102; dilution 1:1,000), rabbit anti-human phospho-p44/42 MAPK antibody (catalog no. 9101; dilution 1:1,000), rabbit anti-human MMP-2 antibody (catalog no. 4022; dilution 1:400), rabbit anti-human MMP-9 antibody (catalog no. 3852; dilution 1:400) (all from Cell Signaling Technology) rabbit anti-human TIMP-1 antibody (catalog no. ab109125; dilution 1:400; Abcam), mouse anti-human $\beta$-actin antibody (catalog no. sc-130301; dilution 1:1,000; Santa Cruz Biotechnology, Santa Cruz, CA, USA).

RNA extraction and quantitative real-time PCR ( $q R T-P C R)$. TRIzol reagent (Invitrogen, Carlsbad, CA, USA) was used for the extraction of total RNA from the PANC-1 cells. Next, cDNA was synthesized using a PrimeScript RT reagent kit and qRT-PCR was carried out using a SYBR-Green PCR kit (both from Takara, Dalian, China), according to the manufacturer's instructions. GAPDH was used as an internal control, and relative expression levels were assessed using the ${ }^{\Delta \Delta} \mathrm{Ct}$ method. PCR primers for qRT-PCR assay were as follows (5'-3'): FGF-2-forward, AGAGCGACCCTCACATCAAG and FGF-2reverse, TCGTTTCAGTGCCACAACG; FGFR-2-forward, TCCTATGACATTAACCGTGTT and FGFR-2-reverse, TTT AACACTGCCGTTTAT; MMP-2-forward, GTGCTGAAG GACACACTAAAGAAGA and MMP-2-reverse, TTGCCATC CTTCTCAAAGTTGTAGG; MMP-9-forward, GCGGAGAT TGGGAACCAGCTGTA and MMP-9-reverse, GACGCGCC TGTGTACACCCACA; TIMP-1-forward, CATCCTGTTGTT GCTGTGGCTGAT and TIMP-1-reverse, GTCATCTTGATC TCATAACGCTGG; MAPK-1-forward, CAGTTCTTGACCC CTGGTCC and MAPK-1-reverse, GTACATACTGCCGCAG GTCA; GAPDH-forward, GGAGCGAGATCCCTCCAAAAT and GAPDH-reverse, GGCTGTTGTCATACTTCTCATGG. All experiments were performed three times in triplicate.

Statistical analysis. Statistical analyses were performed using the SPSS software package (version 13.0; SPSS, Inc., Chicago, IL, USA). All data are presented as mean \pm SEM. Data were analyzed by one-way analysis of variance (ANOVA), and all statistical tests were two-sided. A P-value of $<0.05$ was considered to indicate a statistically significant result.

\section{Results}

Effect of celecoxib and FGF-2 on the proliferation and apoptosis of PANC-1 cells. In the present study, the influence of celecoxib was examined on PANC-1 cell growth. Celecoxib inhibited cell proliferation in a dose- and time-dependent manner (Fig. 1A), and this effect was preventable through the presence of exogenous FGF-2 $(10 \mathrm{ng} / \mathrm{ml})$ in culture medium with celecoxib (Fig. 1B). No inhibitory effect on PANC-1 cell growth was observed within the first $24 \mathrm{~h}$ for celecoxib concentrations of up to $40 \mu \mathrm{mol} / 1$. Longer periods of incubation reduced MTT signals starting at a concentration of $20 \mu \mathrm{mol} / 1$. Hence, for further experiments in vitro, celecoxib concentrations between 5 and $10 \mu \mathrm{mol} / 1$ were used.

The ability of FGF-2 to reverse the inhibitory effect of celecoxib on cell proliferation could be attributable to the inhibition of apoptosis. Celecoxib treatment for $24 \mathrm{~h}$ induced a significant 4-fold increase in the apoptotic index, from $4.8 \pm 1.1 \%$ observed in control untreated cells to $19.84 \pm 1.9 \%$ in cells treated with celecoxib $(10 \mu \mathrm{mol} / \mathrm{l})$ for $24 \mathrm{~h}$ (Fig. 1C and D). FGF-2 alone had no influence on apoptotic level. However, FGF-2 $(10 \mathrm{ng} / \mathrm{ml})$ significantly reduced celecoxib-induced apoptosis from $19.84 \pm 1.9 \%$ in cells treated with celecoxib $(10 \mu \mathrm{mol} / \mathrm{l})$ alone to $11.58 \pm 2.3 \%$ in cells treated with celecoxib and FGF-2.

\section{Celecoxib compromises FGF-2-induced invasion and migra-} tion of PANC-1 cells. Next, the effects of celecoxib on the invasion and migration of PANC-1 cells were investigated. As shown in Fig. 2A, celecoxib (10 $\mu \mathrm{mol} / \mathrm{l})$ strongly inhibited cell invasion and migration. Compared with the control group, the invasion and migration abilities of the PANC-1 cells were significantly decreased $(\mathrm{P}<0.05$; Fig. $2 \mathrm{~B}$ and $\mathrm{C})$. In contrast, treatment with FGF-2 notably enhanced the invasion and migration abilities of the PANC-1 cells. However, when PANC-1 cells were treated with FGF-2 $(10 \mathrm{ng} / \mathrm{ml})$ and cele$\operatorname{coxib}(10 \mu \mathrm{mol} / \mathrm{l})$, the enhanced invasion and migration abilities induced by FGF-2 were abolished by celecoxib (Fig. 2).

Celecoxib inhibits FGF-2 and FGFR-2 expression in PANC-1 cells. The treatment of PANC-1 cells with 5 and $10 \mu \mathrm{mol} / 1$ of celecoxib resulted in a marked suppression in cellular FGF-2 content, as indicated by western blot analysis (Fig. 3). Celecoxib suppressed FGF-2 expression in a dose-dependent manner; that is, after incubation with celecoxib for $12 \mathrm{~h}$, cells expressed a marginally detectable level of FGF-2 (Fig. 3A). However,FGF-2 levels increased rapidly within $8 \mathrm{~h}$ of celecoxib $(10 \mu \mathrm{mol} / \mathrm{l}) \mathrm{removal}$, and returned to normal levels. In contrast, incubation of PANC-1 cells with celecoxib $(10 \mu \mathrm{mol} / \mathrm{l})$ for $12 \mathrm{~h}$ resulted in a significant decrease in FGFR-2 expression; and after removal of celecoxib, FGFR-2 inhibition persisted for some time.

Celecoxib suppresses MMP-9 and MMP-2 expression in PANC-1 cells. Matrix metalloproteinases (MMPs) serve as reliable markers for tumor cell invasion and migration. In the present study, PANC-1 cells were treated with or without $10 \mathrm{ng} / \mathrm{ml}$ of FGF-2 and with or without $10 \mu \mathrm{mol} / 1$ of celecoxib; and mRNA and protein levels of MMP-2, MMP-9 and TIMP-1 were examined by qRT-PCR and western blot analysis, respectively. As shown in Fig. 4, FGF-2 treatment 
A

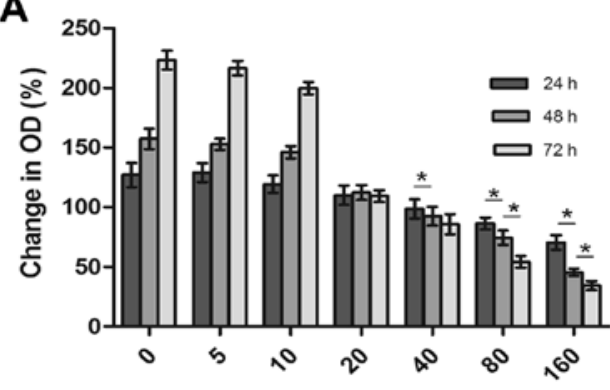

C

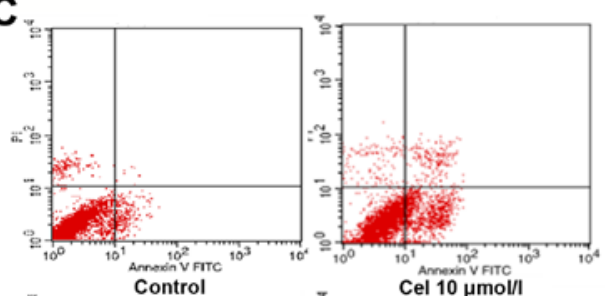

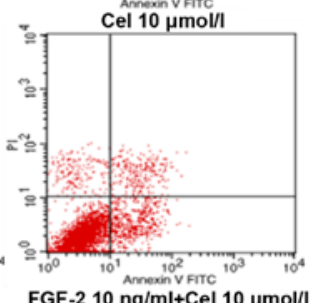

B

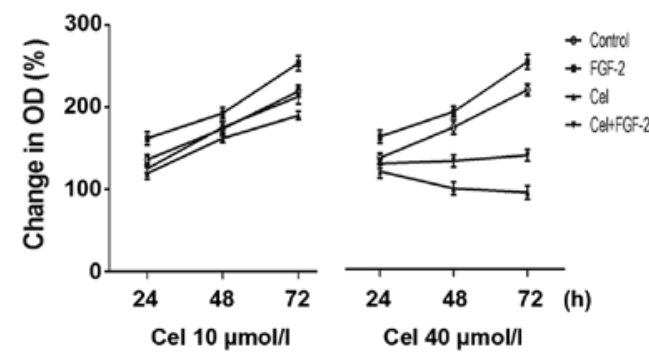

D

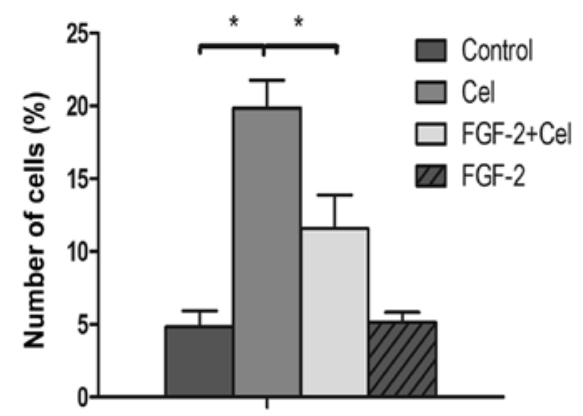

Figure 1. Effect of celecoxib and FGF-2 on the proliferation and apoptosis of PANC-1 cells. (A) Cell viability of PANC-1 cells following treatment with celecoxib at a concentration range of 5-160 $\mu \mathrm{mol} / 1$ for 24,48 and $72 \mathrm{~h}$. (B) Effect of celecoxib (10 and $40 \mu \mathrm{mol} / \mathrm{l})$ and FGF-2 (10 ng/ml) on the proliferation of PANC-1 cells. (C) Effect of celecoxib $(10 \mu \mathrm{mol} / \mathrm{l})$ and FGF-2 $(10 \mathrm{ng} / \mathrm{ml})$ on the apoptosis of PANC-1 cells. (D) The rate of apoptosis of PANC-1 cells in response to different treatments. Cells were stained with FITC-Annexin V/PI. Data are presented as mean \pm SEM of three independent experiments; ${ }^{*} \mathrm{P}<0.05$ represents a significant difference. Cel, celecoxib.
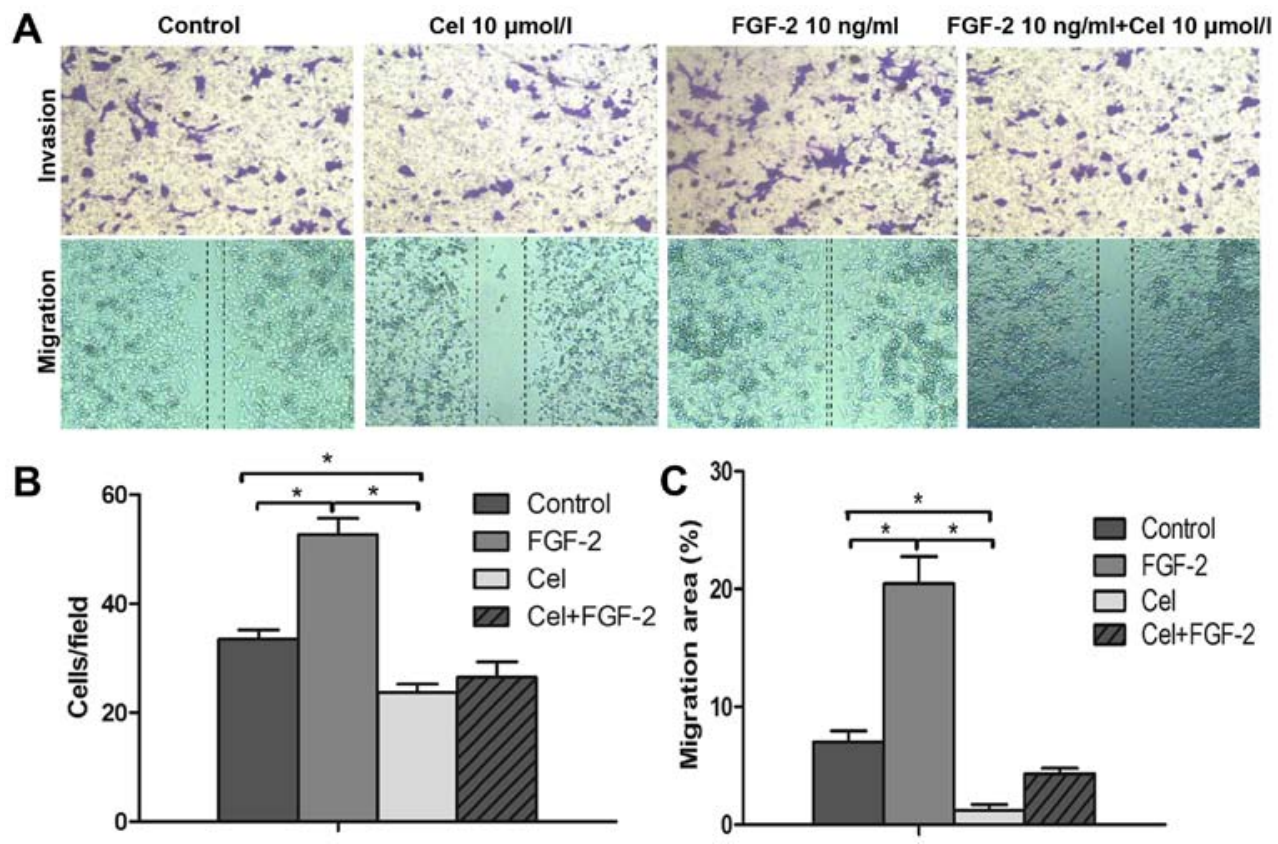

Figure 2. Celecoxib inhibits FGF-2-enhanced PANC-1 cell migration and invasion. (A) The invasive ability of PANC-1 cells on the bottom side of the Transwell membrane at a magnification of x100 and the scratch-wound migration of PANC-1 cells at a magnification of x10. (B) Invasion of PANC-1 cells in response to different treatments. The number of invaded cells was quantified by counting the number of cells from six random fields. (C) Migration area percentage of PANC-1 cells in response to different treatments. The data presented are from three independent experiments; ${ }^{*} \mathrm{P}<0.05$ represents a significant difference. Cel, celecoxib.

resulted in increased MMP-2 and MMP-9 protein expression, compared to the untreated control cells. In contrast, western blot and qRT-PCR analyses revealed that the expression levels of MMP-2 and MMP-9 were significantly decreased in 


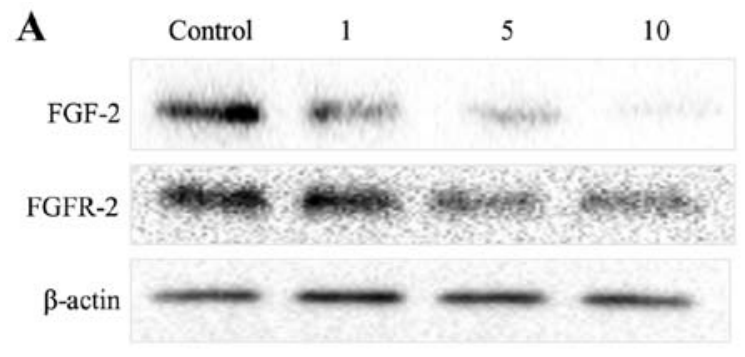

Different concentrations $(\mu \mathrm{mol} / \mathrm{l})$ of celecoxib incubation for $12 \mathrm{~h}$

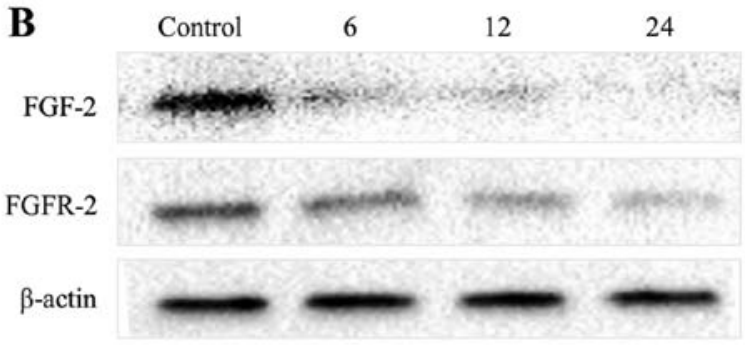

Time after celecoxib $(10 \mu \mathrm{mol} / 1)$ incubation (h)

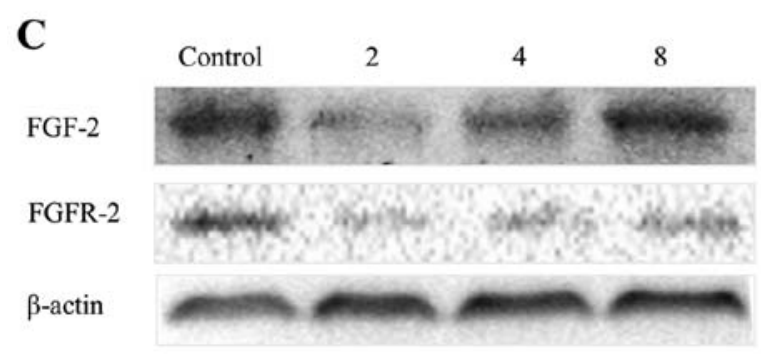

Time after celecoxib $(10 \mu \mathrm{mol} / 1)$ removal (h)

Figure 3. Western blot analysis of the influence of celecoxib on FGF-2 and FGFR-2 expression in PANC-1 cells. (A) The influence of different celecoxib concentrations on FGF-2 and FGFR-2 expression. (B) The influence of different incubation times of PANC-1 cells with celecoxib $(10 \mu \mathrm{mol} / \mathrm{l})$ on the expression of FGF-2 and FGFR-2. (C) PANC-1 cells were incubated with $10 \mu \mathrm{mol} / 1$ of celecoxib for $12 \mathrm{~h}$, and the expression of FGF-2 and FGFR-2 was measured at indicated times after celecoxib removal. Cel, celecoxib.

A

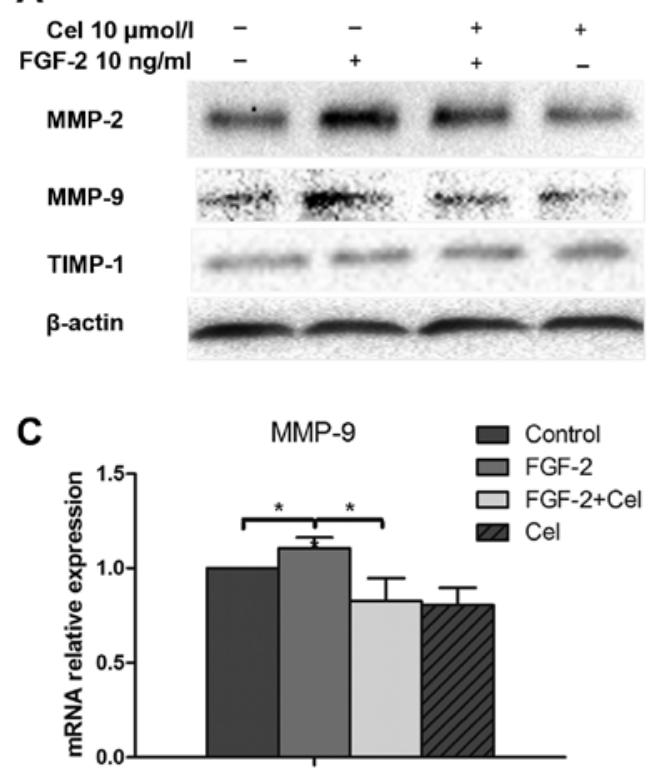

B

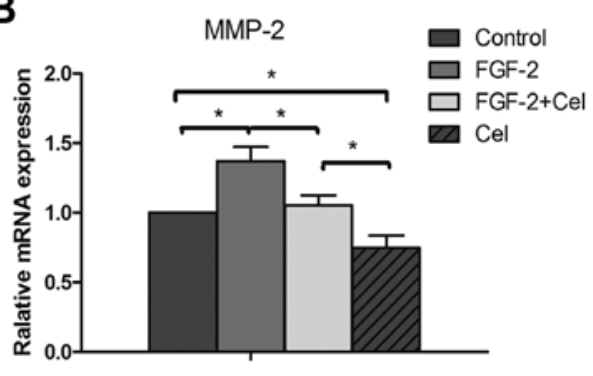

D

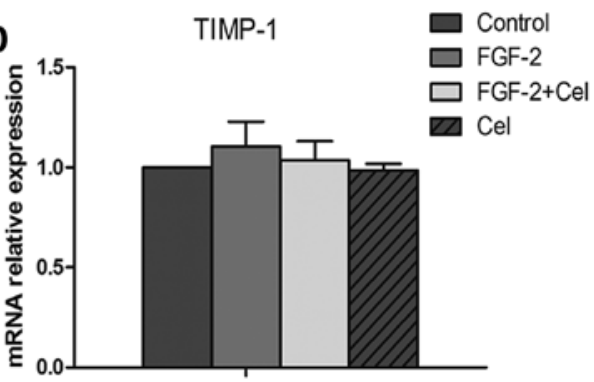

Figure 4. A 24-h celecoxib (10 $\mu \mathrm{mol} / 1)$ treatment reduces FGF-2 (10 ng/ml)-mediated enhancement of MMP-2 and MMP-9 in PANC-1 cells. (A) Western blot analysis of the expression levels of MMP-2, MMP-9 and TIMP-1. (B) The qRT-PCR analysis of MMP-2 mRNA expression. (C) The qRT-PCR analysis of MMP-9 mRNA expression. (D) The qRT-PCR analysis of TIMP-1 mRNA expression; ${ }^{*} \mathrm{P}<0.05$ represents a significant difference. Cel, celecoxib.

cells exposed to $10 \mu \mathrm{mol} / 1$ of celecoxib (P<0.05; Fig. 4A-C), compared with the control cells. No change in TIMP-1 expression was observed when PANC-1 cells were treated with FGF-2 or celecoxib alone or in combination (Fig. 4D). Celecoxib was also able to suppress the FGF-2-induced enhanced expression of MMP-2 and MMP-9, which is suggestive of its anti-FGF-2like capacity (Fig. 4A-C).

Celecoxib inhibits FGFR-2 expression and ERK1/2 phosphorylation activated by $F G F-2$. Mitogenic signaling through FGFRs often involves the activation of the MAPK pathway. Therefore, we sought to determine whether the FGF-2-mediated activation of MAPK was altered as a consequence of changes in FGFR-2 levels. Western blot analysis revealed that FGF-2 treatment caused the increase in its receptor FGFR-2 expression, as well as increased levels of phosphorylated ERK, compared to the control untreated PANC-1 cells (Fig. 5A). In contrast, treatment with celecoxib inhibited FGFR-2 expression and suppressed phosphorylated ERK1/2 altered by FGF-2. In addition, qRT-PCR analyses also revealed that the transcriptional activity of FGFR-2 and MAPK1 decreased in the cells treated with celecoxib, compared to the cells in the control group $(\mathrm{P}<0.05$; Fig. 5B and $\mathrm{C})$.

\section{Discussion}

Pancreatic ductal adenocarcinoma (PDAC) is a very aggressive and lethal type of tumor, in which its metastatic invasion 
A

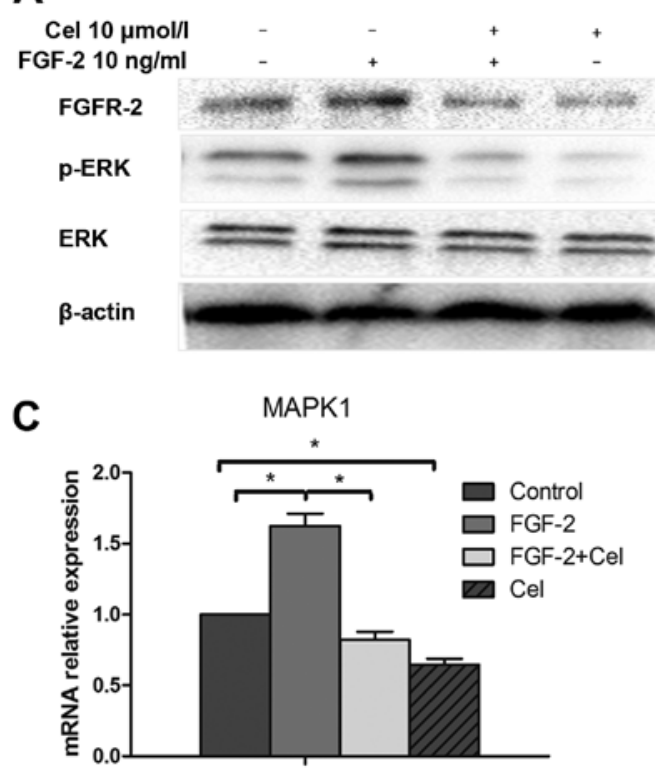

B

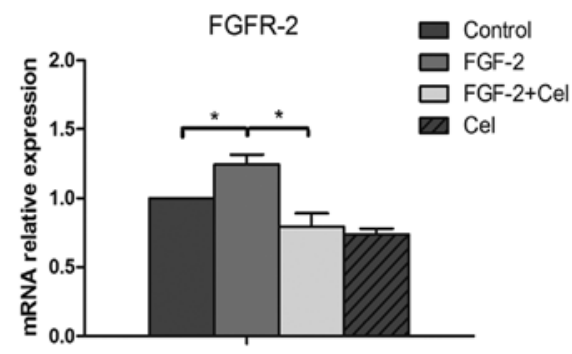

Figure 5. A 24-h celecoxib (10 $\mu \mathrm{mol} / \mathrm{l})$ treatment reduces the FGF-2-mediated enhancement of ERK1/2 protein phosphorylation and FGFR-2 expression. (A) Western blot analysis. Celecoxib downregulates phosphorylated ERK1/2 protein and FGFR-2 expression induced by FGF-2. (B) The qRT-PCR analysis of FGFR-2 mRNA expression (C) The qRT-PCR analysis of MAPK-1 mRNA expression; ${ }^{*} \mathrm{P}<0.05$ represents a significant difference. $\mathrm{Cel}$,celecoxib.

is associated with inflammation (20). The COX-2 enzyme is an important mediator of prostaglandin synthesis and is significantly overexpressed in many different types of cancers (21). COX-2 inhibitors can exert their effects by decreasing the expression of COX-2. Nevertheless, some selective COX-2 inhibitors can also provoke responses in COX-2-negative cancer cells, which could not be explained by COX-2 inhibition, However, the mechanisms of this biological effects are poorly understood (22). Celecoxib, a selective COX-2 inhibitor, has been previously shown to inhibit the growth of human pancreatic cancer cell lines (23). In addition, in pancreatic xenograft experiments, treatment with celecoxib inhibited tumor growth, metastasis and angiogenesis (24). Furthermore, in a clinical assessment study of celecoxib pharmacodynamics in pancreatic cancer patients, celecoxib significantly decreased the level of COX and PGE2; but this effect did not induce a significant decrease in tumor growth, suggesting that COX and PGE2 downregulation may be irrelevant for pancreatic cancer growth (25). Moreover, there is evidence suggesting that the mechanism of the antitumor effect of celecoxib may be mediated by targets other than COX-2 such as the downregulation of the expression of survivin (26) or AKT (27). It has been previously reported that PANC-1 cells express a marginally detectable level of COX-2 (28); however, COX-2 inhibitors continue to exert an antitumor effect in these cells. In the present study, we investigated the possible regulation of FGF-2 and its receptor by selective COX-2 inhibitor celecoxib, as well as the role of FGF-2 in the survival, proliferation, invasion and migration of PANC-1 cells. We demonstrated that celecoxib significantly inhibited cell proliferation and stimulated apoptosis in PANC-1 cells. This was accompanied by a profound but reversible suppression of FGF-2 expression in PANC-1 cells. Furthermore, the addition of exogenous FGF-2 to culture medium significantly ameliorated the antiproliferative and pro-apoptotic effects of celecoxib in PANC-1 cells. These data suggest that in PANC-1 cells, COX-2 inhibitor celecoxib suppresses cell proliferation and induces apoptosis, at least in part, via an FGF-2-dependent pathway. FGF-2 is an important growth and differentiation factor involved in many physiological and pathological processes. Indeed, it has been shown in several studies that the tissue-specific expression of FGFs and FGFRs is critical in the regulation of tissue homeostasis (7-10). The ectopic expression of FGF ligands or aberrant splicing of FGFRs can result in the activation of autocrine signaling pathways and cause uncontrolled cell proliferation (29). Moreover, FGFR-2 overexpression was correlated with increased pancreatic cancer cell proliferation, invasion and early liver recurrence in patients following surgical resection of a tumor (30).

Invasion and metastasis are two hallmarks of cancer, the main causes of cancer-related death, and the most difficult clinical treatment issues, particularly in $\operatorname{PDAC}(3,4)$. Numerous studies that explored these processes in PDAC have been conducted over several decades, but tumor metastasis continues to remain the main cause of poor outcome in PDAC patients (31-33). In recent years, studies focusing on the tumor microenvironment suggest that the remodeling of the tumor extracellular matrix (ECM) increases the invasion and metastatic capabilities of tumor cells (32). Among numerous factors involved in ECM remodeling, MMPs secreted by cancer cells have been postulated as one of the major facilitators of tumor invasion (33). Compared to benign tumors, malignant tumors exhibit increased MMP expression levels, which lead to the increased degradation of the ECM and promotion of tumor cell migration and invasion (34). Indeed, the upregulation of the expression of MMPs and TIMPs in cancer tissues results in increased tumor invasion and metastasis (35). The elevated expression of MMP-2 or MMP-9 is associated with the hydrolysis of the ECM and induction of cancer cell invasion through the basement membrane (36). The results of the present study revealed that celecoxib can inhibit FGF-2 signaling pathwaymediated MMP regulation in PANC-1 cells during tumor cell invasion in vitro. Our data revealed that the expression levels of MMP-2 and MMP-9 were decreased in the PANC-1 cells when treated with celecoxib. In contrast, the expression levels of MMP-2 and MMP-9 were significantly induced by FGF-2 
treatment. It has been reported that many patients with pancreatic cancer overexpress FGF-2, which leads to the activation of the ERK1/2 pathway, increased expression of MMPs and higher invasive potential (9-11). In addition, in the present study, TIMP-1 levels did not change after celecoxib treatment, suggesting that a different pathway is involved in the regulation of TIMP-1 expression in PANC-1 cells.

The MAPK/ERK signaling pathway is one of the most commonly activated pathways in human cancers (37). It has been shown that this pathway, particularly ERK1/2, regulates the expression of MMPs (38). Indeed, a decrease in ERK1/2 phosphorylation may be involved in the downregulation of MMPs and upregulation of the expression of TIMPs (39). In the present study, we showed that ERK1/2 was activated in PANC-1 cells following treatment with FGF-2. In addition, FGF-2 increased PANC-1 cell growth and invasion via binding to its receptor FGFR-2 and phosphorylation of the ERK1/2 protein, which further resulted in increased secretion of MMP-2 and MMP-9. In contrast, treatment with celecoxib suppressed the expression of FGFR-2, inhibited ERK1/2 phosphorylation and acted against the effect of FGF-2; suggesting that the molecular mechanisms of celecoxib inhibition in PANC-1 cell invasion and migration are related to the ERK1/2 pathway and mediated by FGFR-2. Another possible mechanism is the involvement of the Ras-MAPK signaling pathway. Pancreatic adenocarcinoma has the highest incidence of K-ras point mutations (70-90\% of all cases) (40), and PANC-1 cells have an activating K-ras gene and it has been shown that $\mathrm{K}$-ras is involved in increasing or activating extracellularly sequestered FGF-2 (41). In addition, oncogenic Ras-induced proliferation can be abolished by addition of an anti-FGF-2 blocking antibody (41). Based on these findings we hypothesized that the antitumor effects of celecoxib may also be associated with K-ras regulation in PANC-1 cells.

In conclusion, the present study is the first to report on the relationship between FGF-2 expression and COX-2 inhibitor celecoxib in PANC-1 cells. The antitumor effect of celecoxib was exerted through the inhibition of the expression of FGFR-2 and interruption of the activity of MMPs. These results provide a rational basis for the further evaluation of the efficacy of celecoxib in the treatment of PDAC and perhaps other malignancies, in which FGF2/FGFR2 signaling has an important role.

\section{References}

1. Jemal A, Siegel R, Ward E, Murray T, Xu J and Thun MJ: Cancer statistics, 2007. CA Cancer J Clin 57: 43-66, 2007.

2. Siegel RL, Miller KD and Jemal A: Cancer statistics, 2015. CA Cancer J Clin 65: 5-29, 2015.

3. Sun H, Ma H, Hong G, Sun H and Wang J: Survival improvement in patients with pancreatic cancer by decade: A period analysis of the SEER database, 1981-2010. Sci Rep 4: 6747, 2014.

4. Sohn TA, Yeo CJ,Cameron JL, Koniaris L, Kaushal S, Abrams RA Sauter PK, Coleman J, Hruban RH and Lillemoe KD: Resected adenocarcinoma of the pancreas-616 patients: Results, outcomes, and prognostic indicators. J Gastrointest Surg 4: 567-579, 2000.

5. Cho K, Ishiwata T, Uchida E, Nakazawa N, Korc M, Naito Z and Tajiri T: Enhanced expression of keratinocyte growth factor and its receptor correlates with venous invasion in pancreatic cancer. Am J Pathol 170: 1964-1974, 2007.

6. Beenken A and Mohammadi M: The FGF family: Biology, pathophysiology and therapy. Nat Rev Drug Discov 8: 235-253, 2009.
7. August P, Javerzat $\mathrm{S}$ and Bikfalvi A: Regulation of vascular development by fibroblast growth factors. Cell Tissue Res 8: 204-210, 2003.

8. Powers CJ, McLeskey SW and Wellstein A: Fibroblast growth factors, their receptors and signaling. Endocr Relat Cancer 7: $165-197,2000$.

9. Turner $\mathrm{N}$ and Grose R: Fibroblast growth factor signalling: From development to cancer. Nat Rev Cancer 10: 116-129, 2010.

10. Matsuda Y, Yoshimura H, Suzuki T, Uchida E, Naito Z and Ishiwata T: Inhibition of fibroblast growth factor receptor 2 attenuates proliferation and invasion of pancreatic cancer. Cancer Sci 105: 1212-1219, 2014

11. Nandy D and Mukhopadhyay D: Growth factor mediated signaling in pancreatic pathogenesis. Cancers 3: 841-871, 2011.

12. Corson LB, Yamanaka Y, Lai KM and Rossant J: Spatial and temporal patterns of ERK signaling during mouse embryogenesis. Development 130: 4527-4537, 2003.

13. Morita I: Distinct functions of COX-1 and COX-2. Prostaglandins Other Lipid Mediat 68-69: 165-175, 2002.

14. Steinbach G, Lynch PM, Phillips RK, Wallace MH, Hawk E, Gordon GB, Wakabayashi N, Saunders B, Shen Y, Fujimura T, et al: The effect of celecoxib, a cyclooxygenase-2 inhibitor, in familial adenomatous polyposis. N Engl J Med 342: 1946-1952, 2000.

15. Kirane A, Toombs JE, Ostapoff K, Carbon JG, Zaknoen S, Braunfeld J, Schwarz RE, Burrows FJ and Brekken RA: Apricoxib, a novel inhibitor of COX-2, markedly improves standard therapy response in molecularly defined models of pancreatic cancer. Clin Cancer Res 18: 5031-5042, 2012.

16. Sánchez-Fidalgo S, Martín-Lacave I, Illanes M and Motilva V: Angiogenesis, cell proliferation and apoptosis in gastric ulcer healing. Effect of a selective cox-2 inhibitor. Eur J Pharmacol 505: 187-194, 2004

17. Sawaoka H, Tsuji S, Tsujii M, Gunawan ES, Sasaki Y, Kawano S and Hori M: Cyclooxygenase inhibitors suppress angiogenesis and reduce tumor growth in vivo. Lab Invest 79: 1469-1477, 1999.

18. Baguma-Nibasheka M, Barclay C, Li AW, Geldenhuys L, Porter GA, Blay J, Casson AG and Murphy PR: Selective cyclooxygenase-2 inhibition suppresses basic fibroblast growth factor expression in human esophageal adenocarcinoma. Mol Carcinog 46: 971-980, 2007.

19. Lei J, Ma J, Ma Q, Li X, Liu H, Xu Q, Duan W, Sun Q, Xu J, $\mathrm{Wu} \mathrm{Z}$, et al: Hedgehog signaling regulates hypoxia induced epithelial to mesenchymal transition and invasion in pancreatic cancer cells via a ligand-independent manner. Mol Cancer 12: 66, 2013.

20. Jamieson NB, Mohamed M, Oien KA, Foulis AK, Dickson EJ, Imrie CW, Carter CR, McKay CJ and McMillan DC: The relationship between tumor inflammatory cell infiltrate and outcome in patients with pancreatic ductal adenocarcinoma. Ann Surg Oncol 19: 3581-3590, 2012.

21. Mohammed A, Janakiram NB, Madka V, Brewer M, Ritchie RL, Lightfoot S, Kumar G, Sadeghi M, Patlolla JM, Yamada HY, et al: Targeting pancreatitis blocks tumor-initiating stem cells and pancreatic cancer progression. Oncotarget 6: 15524-15539, 2015.

22. Barlow M, Edelman M, Glick RD, Steinberg BM and Soffer SZ: Celecoxib inhibits invasion and metastasis via a cyclooxygenase 2-independent mechanism in an in vitro model of Ewing sarcoma. J Pediatr Surg 47: 1223-1227, 2012.

23. El-Rayes BF, Ali S, Sarkar FH and Philip PA: Cyclooxygenase 2-dependent and -independent effects of celecoxib in pancreatic cancer cell lines. Mol Cancer Ther 3: 1421-1426, 2004.

24. Wei D, Wang L, He Y, Xiong HQ, Abbruzzese JL and Xie K: Celecoxib inhibits vascular endothelial growth factor expression in and reduces angiogenesis and metastasis of human pancreatic cancer via suppression of $\mathrm{Sp} 1$ transcription factor activity. Cancer Res 64: 2030-2038, 2004.

25. Jimeno A, Amador ML, Kulesza P, Wang X, Rubio-Viqueira B, Zhang X, Chan A, Wheelhouse J, Kuramochi H, Tanaka K, et al: Assessment of celecoxib pharmacodynamics in pancreatic cancer. Mol Cancer Ther 5: 3240-3247, 2006

26. Pyrko P, Soriano N, Kardosh A, Liu YT, Uddin J, Petasis NA, Hofman FM, Chen CS, Chen TC and Schönthal AH: Downregulation of survivin expression and concomitant induction of apoptosis by celecoxib and its non-cyclooxygenase-2-inhibitory analog, dimethyl-celecoxib (DMC), in tumor cells in vitro and in vivo. Mol Cancer 5: 19, 2006 
27. Pal I and Mandal M: GSK690693 enhances Celecoxib mediated apoptosis by an Akt mediated pathway in colon cancer. Cancer Res 73 (Suppl 8): S1044, 2013.

28. Molina MA, Sitja-Arnau M, Lemoine MG, Frazier ML and Sinicrope FA: Increased cyclooxygenase-2 expression in human pancreatic carcinomas and cell lines: Growth inhibition by nonsteroidal anti-inflammatory drugs. Cancer Res 59: 4356-4362, 1999.

29. Marek L, Ware KE, Fritzsche A, Hercule P, Helton WR, Smith JE, McDermott LA, Coldren CD, Nemenoff RA, Merrick DT, et al: Fibroblast growth factor (FGF) and FGF receptor-mediated autocrine signaling in non-small-cell lung cancer cells. Mol Pharmacol 75: 196-207, 2009.

30. Ishiwata T, Matsuda Y, Yamamoto T, Uchida E, Korc M and Naito Z: Enhanced expression of fibroblast growth factor receptor 2 IIIc promotes human pancreatic cancer cell proliferation. Am J Pathol 180: 1928-1941, 2012.

31. Shrikhande SV, Kleeff J, Reiser C, Weitz J, Hinz U, Esposito I, Schmidt J, Friess H and Büchler MW: Pancreatic resection for M1 pancreatic ductal adenocarcinoma. Ann Surg Oncol 14: 118-127, 2007.

32. Friedl $P$ and Alexander S: Cancer invasion and the microenvironment: Plasticity and reciprocity. Cell 147: 992-1009, 2011.

33. Kessenbrock K, Plaks V and Werb Z: Matrix metalloproteinases: Regulators of the tumor microenvironment. Cell 141: 52-67, 2010.

34. Shah N, Jin K, Cruz LA, Park S, Sadik H, Cho S, Goswami CP, Nakshatri H, Gupta R, Chang HY, et al: HOXB13 mediates tamoxifen resistance and invasiveness in human breast cancer by suppressing ER $\alpha$ and inducing IL-6 expression. Cancer Res 73 . 5449-5458, 2013.
35. Shao W, Wang W, Xiong XG, Cao C, Yan TD, Chen G, Chen H, Yin W, Liu J, Gu Y, et al: Prognostic impact of MMP-2 and MMP-9 expression in pathologic stage IA non-small cell lung cancer. J Surg Oncol 104: 841-846, 2011.

36. Egeblad $\mathrm{M}$ and Werb $\mathrm{Z}$ : New functions for the matrix metalloproteinases in cancer progression. Nat Rev Cancer 2: 161-174, 2002.

37. Kim HS, Kim MJ, Kim EJ, Yang Y, Lee MS and Lim JS: Berberine-induced AMPK activation inhibits the metastatic potential of melanoma cells via reduction of ERK activity and COX-2 protein expression. Biochem Pharmacol 83: 385-394, 2012.

38. Guo J, Xu Y, Ji W, Song L, Dai C and Zhan L: Effects of exposure to benzo[a]pyrene on metastasis of breast cancer are mediated through ROS-ERK-MMP9 axis signaling. Toxicol Lett 234: 201-210, 2015

39. Zhong HM, Ding QH, Chen WP and Luo RB: Vorinostat, a HDAC inhibitor, showed anti-osteoarthritic activities through inhibition of iNOS and MMP expression, p38 and ERK phosphorylation and blocking NF- $\kappa \mathrm{B}$ nuclear translocation. Int Immunopharmacol 17: 329-335, 2013.

40. Longnecker DS and Terhune PG: What is the true rate of K-ras mutation in carcinoma of the pancreas? Pancreas 17: 323-324, 1998.

41. Fedorov YV, Rosenthal RS and Olwin BB: Oncogenic Ras-induced proliferation requires autocrine fibroblast growth factor 2 signaling in skeletal muscle cells. J Cell Biol 152: $1301-1305,2001$ 